\title{
A ATUAÇÃO DE ORGANIZAÇÕES NÃO GOVERNAMENTAIS NA INCIDÊNCIA VIOLÊNCIA DE GÊNERO NA ÁFRICA DO SUL
}

\author{
Jaiandra Maina Queiroz Furtado
}

\begin{abstract}
RESUMO
O trabalho é fruto de estudos realizados no Curso de Relações Internacionais, em um período de mobilidade cursado na Universidade de Brasília (2019), na disciplina de Relações Internacionais da África, no qual nos debruçamos para um melhor discernimento, sobre o alto índice de violência de gênero, em que a mulher é submetida. Através de análises bibliográficas, entrevistas, pesquisas aprofundadas em jornais, sites, revistas e outras fontes. Lançamos um olhar esmiuçante nos elementos da Constituição da África do Sul de 1996, e relatórios internacionais, como "Crime against Women in South Africa" e "In depth study on all forms of violence against women". Dados da Organização Mundial da Saúde (OMS) e Organização das Nações Unidas (ONU) também estão presentes. Entre alguns autores utilizados estão, Giane Bosseli (2004), Pierre Bordieu (2005), Silva (2013), Caresia (2007), Stone (2008), entre outros. O texto produzido, dispõe de dados obtidos em uma entrevista (2019), realizada com o Professor Doutor em História das Relações Internacionais Pio Penna Filho, sobre a atuação das ONGs no território da África do Sul. Apesar de serem evidentes os esforços para minimizar o problema da violência e mesmo com a atuação e instalação de diversas ONGs pelo país sul africano, constata-se que nem todas as vítimas são amparadas, ainda há um déficit alto quanto ao atendimento das pessoas violadas, principalmente em relação as instituições governamentais. Dentre muitas justificativas, isso ocorre, por conta de algumas vítimas não se sentirem seguras para relatarem, ou porque moram em lugares mais afastados - onde o acesso aos atendimentos é mais difícil - mas também ocorre pelo desconhecimento de lugares na qual possa recorrer em casos de violência.
\end{abstract}

Palavras-chaves: violência; mulher; gênero;

\section{THE PERFORMANCE OF NON-GOVERNMENTAL ORGANIZATIONS IN THE INCIDENCE OF GENDER VIOLENCE IN SOUTH AFRICA}

\begin{abstract}
The work is the result of studies carried out in the International Relations Course, during a mobility period taken at the University of Brasilia (2019), in the discipline of International Relations in Africa, in which we focus on better discernment on the high rate of violence. gender, to which women are subjected. Through bibliographic analysis, interviews, in-depth searches in newspapers, websites, magazines and other sources. We cast a scrutinizing look at the elements of the 1996 South African Constitution, and international reports such as "Crime against Women in South Africa" and "In depth study on all forms of violence against women". Data from the World Health Organization (WHO) and the United Nations (UN) are also present. Among some authors used are, Giane Bosseli (2004), Pierre Bordieu (2005), Silva (2013), Caresia (2007), Stone (2008), among others. The text produced has data obtained in an interview (2019), conducted with Professor Doctor in History of International Relations Pio Penna Filho, on the role of NGOs in the territory of South Africa. Despite efforts to minimize the problem of violence and even with the performance and installation of several NGOs across the South African country, it appears that not all victims are supported, there is still a high deficit in the care of the violated people, especially in relation to government institutions. Among many justifications, this occurs, due to the fact that some victims do not feel safe to report, or because they live in more distant places - where access to care is more difficult - but it also occurs due to the lack of places in which they can resort in cases of violence.
\end{abstract}

Keywords violence; women; gender; 


\title{
EL DESEMPEÑO DE LAS ORGANIZACIONES NO GUBERNAMENTALES EN LA INCIDENCIA DE LA VIOLENCIA DE GÉNERO EN SUDÁFRICA
}

\begin{abstract}
RESUMEN
El trabajo es el resultado de estudios realizados en el Curso de Relaciones Internacionales, durante un período de movilidad realizado en la Universidad de Brasilia (2019), en la disciplina de Relaciones Internacionales en África, en el que nos enfocamos en un mejor discernimiento sobre la alta tasa de violencia de género a la que están sometidas las mujeres. Mediante análisis bibliográficos, entrevistas, búsquedas en profundidad en periódicos, sitios web, revistas y otras fuentes. Echamos una mirada escrutadora a los elementos de la Constitución de Sudáfrica de 1996 y a informes internacionales como "Crimen contra la mujer en Sudáfrica" y "Estudio en profundidad sobre todas las formas de violencia contra la mujer". También están presentes datos de la Organización Mundial de la Salud (OMS) y las Naciones Unidas (ONU). Entre algunos autores utilizados se encuentran, Giane Bosseli (2004), Pierre Bordieu (2005), Silva (2013), Caresia (2007), Stone (2008), entre otros. El texto elaborado cuenta con datos obtenidos en una entrevista (2019), realizada con la profesora Doctora en Historia de las Relaciones Internacionales Pio Penna Filho, sobre el papel de las ONG en el territorio de Sudáfrica. A pesar de los esfuerzos por minimizar el problema de la violencia e incluso con el actuación e instalación de varias ONG en todo el país sudafricano, parece que no todas las víctimas son apoyadas, aún existe un alto déficit en la atención de las personas violadas, especialmente en relación a las instituciones gubernamentales. Entre muchas justificaciones, esto ocurre, por el hecho de que algunas víctimas no se sienten seguras para denunciar, o porque viven en lugares más distantes -donde el acceso a la atención es más difícil- pero también ocurre por la falta de lugares en los que pueden recurrir en casos de violencia.
\end{abstract}

Palabras llave: violencia; mujeres; género;

\section{Introd ução}

Apesar das mudanças acirrarem-se com vertiginosa rapidez, ao longo dos anos, algumas conjunturas tornaram-se permanentes e estagnadas. Neste ínterim, padrões sistêmicos no meio social são elaborados e acabam perpassando por gerações. Entre esses padrões, nota-se que a sobrepujança masculina em relação a mulher se faz presente e compõe um cenário internacional de desigualdade entre gêneros.

Apesar do problema manifestar-se em escala mundial, o artigo tem como centro de análise, a incidência de violência de gênero na África do Sul, visto que o país apresenta índices elevados quanto a desigualdade entre homens e mulheres. Logo, busca-se compreender as raízes do problema e as consequências nas estruturas sociais, nas instituições, no Estado, na cultura, entre outros.

É indispensável ressaltar que o tema também surgiu através de uma inquietação quanto a atuação de inúmeras Organizações não Governamentais na África do Sul direcionadas ao contexto de violência de gênero. Nesse aspecto, percebeu-se fragilidade nas respostas estatais 
para amenizar ou cessar o problema, portanto, criaram-se lacunas na proteção das mulheres que tornaram mais acessível a atuação das ONGs no país.

Para um melhor discernimento, o artigo está pautado em análises bibliográficas, entrevistas, pesquisas aprofundadas em jornais, sites, revistas e outras fontes. Além disso, foram empregues elementos da Constituição da África do Sul de 1996, e relatórios internacionais, como "Crime against Women in South Africa" e "In depth study on all forms of violence against women”. Dados da Organização Mundial da Saúde (OMS) e Organização das Nações Unidas (ONU) também estão presentes.

Entre alguns autores utilizados estão, Giane Bosseli (2004), Pierre Bordieu (2005), Silva (2013), Caresia (2007), Stone (2008). O artigo dispõe de uma entrevista, realizada dia 2 de julho de 2019, com o Professor Doutor em História das relações Internacionais Pio Penna Filho, no qual respondeu, presencialmente, perguntas relacionadas a atuação das ONGs no território da África do Sul.

Ademais, entender esta realidade de descaso, quebra dos direitos humanos e a atuação de organismos não estatais no país, pressupõe ultrapassar as fronteiras materiais e ideias preconcebidas. Por conseguinte, é necessário interpretar por diferentes campos do conhecimento a problemática da desigualdade de gênero, pois ela é socialmente produzida no tempo e no espaço, pelas relações entre indivíduos em constante mudança.

\section{As escalas hierárquicas de dominação, desigualdade e violência de gênero}

Ao longo da história humana, através de múltiplas culturas, a desigualdade de gênero fez-se presente na raiz das relações sociais, econômicas e políticas. Nesse ínterim, criaram-se redes de submissão da mulher para com o homem, nos mais diferentes aspectos dentro da sociedade. Podemos afirmar que a mulher vem sendo socialmente oprimida de acordo com valores específicos de determinadas épocas, influenciados pelas principais instituições sociais que contribuíram e contribuem para disseminar a ideia de que esta é um ser inferior, frágil e com instintos de proteção apenas. (BALESTERO, GOMES, 2015, p.45)

Perpetua-se a parcialidade através das estruturas organizacionais, pois a mulher encontra-se sujeita primeiro a tutela de um familiar paternal, depois a um cônjuge, logo então, se alcançada a empregabilidade, subjugada a um chefe. Nesse cenário, observa-se a sobrepujança masculina nas posições ligadas diretamente às tomadas de decisões, nas esferas 
privadas e públicas. Como consequência, lapidaram-se microrrelações de poder favoráveis a um sistema patriarcal e, consequentemente, nocivo e arbitrário.

O sistema apresenta-se danoso visto que, as diferenças entre ambos os gêneros foram transformadas em escalas hierárquicas de dominação, que resultam em atentados físicos e psicológicos. A transgressão física é uma externalidade das estruturas de dominância, na qual ocorre a violação corporal por meio de estupros, agressões, torturas e assassinatos. Além dessas hostilidades, verifica-se a agressão psicológica como um agravante nos problemas enfrentados pelas mulheres, em inúmeras sociedades.

Não obstante, a violência simbólica é imperceptível, a maior parte de sistemas de dominação são naturalizadas, o Estado, as instituições acabam por legitimar e, sobre isto em sua obra "A dominação masculina", o sociólogo Pierre Bourdieu (2005) enfatiza suas observações sobre o que viu em uma pesquisa etnográfica, realizada ao norte da África:

\begin{abstract}
Sempre vi na dominação masculina, e no modo como é imposta e vivenciada, o exemplo por excelência desta submissão paradoxal, resultante daquilo que eu chamo de violência simbólica, violência suave, insensível, invisível a suas próprias vítimas, que se exerce essencialmente pelas vias puramente simbólicas da comunicação e do conhecimento, ou, mais precisamente, do desconhecimento, do reconhecimento ou, em última instância, do sentimento. (p.7-8)
\end{abstract}

Com o desenvolvimento das relações globais, verificou-se semelhanças e diferenças entre alguns países, no que tange a desigualdade de gênero. Conforme o relatório "In depth study on all forms of violence against women" da Organização das Nações Unidas (ONU), "não há uma região do mundo, nenhum país e nenhuma cultura em que a liberdade das mulheres da violência tenha sido assegurada". Ou seja, apesar de particularidades, há um panorama internacional de violação da integridade feminina.

\title{
3 Violência de gênero na África do Sul
}

No continente africano, a África do Sul destaca-se mundialmente pelos elevados índices de violência contra mulheres. De acordo com dados concedidos em 2016 pela Organização Mundial da Saúde (OMS), o número de feminicídios no país ultrapassa a média mundial, pois para cada 100 mil mulheres sul africanas, 12,1 são assassinadas. Não obstante, recentemente os dados foram atualizados e demonstraram um aumento de 11\% em 2017 e 2018. 
$\mathrm{Na}$ imprensa internacional, as manchetes estampam uma realidade obscura e muitas vezes desconhecida. Alguns sites e jornais publicaram matérias sobre o alto índice de violência de gênero na África do Sul, como o "South Coast Herald” que em em 7 de setembro de 2018 tinha o seguinte título como capa "Surge in sexual assault and violence has led to South Africa being dubbed 'the rape capital of the world". Além dele, em 2000, o jornal Folha de São Paulo descreveu a situação do país como uma “epidemia", e em 2018 o "Daily Maverick” relatou a impunidade no país.

Conforme o relatório "Crime against Women in South Africa", realizado em junho de 2018, a percentagem de indivíduos que experimentaram qualquer tipo de crime em 2016/2017 foi de 3,6\% para mulheres e 3,9\%. Contudo, ainda segundo o relatório, dentre esses crimes, para cada 100 mil mulheres, 250 foram vítimas de crimes sexuais, enquanto, para cada 100 mil homens, 120 foram vítimas de crimes sexuais. Por ano, aproximadamente 50 mil casos de violência contra mulheres são registrados, segundo a OMS. Estima-se que esse número seja maior, em virtude dos não registrados, por motivos de impunidade ante os agressores, a dependência feminina e o descaso do sistema de segurança.

Em teoria, a Constituição da República da África do Sul de 1996 dispõe de um conjunto de normas assecuratórias da igualdade, integridade e liberdade de qualquer indivíduo pertencente ao país. De acordo com o Capítulo $2^{\circ}$, seção $9^{a}$, parágrafo $1^{\circ}$ da constituição:

Everyone is equal before the law and has the right to equal protection and benefit of the law.", mais adiante, na mesma seção, parágrafo $2^{\circ}$, afirma: "The state may not unfairly discriminate directly or indirectly against anyone on one or more grounds, including race, gender, sex, pregnancy, marital status, ethnic or social origin, colour, sexual orientation, age, disability, religion, conscience, belief, culture, language and birth. (1996).

Os procedimentos para ratificar a igualdade de gênero não possuem vigor no país, visto que, mesmo com a promulgação das leis, a violência perante esse grupo continua aumentando. Os fundamentos para esse cenário encontram-se na disposição da população sul africana, no qual, fatores como distribuição de renda, raça, escolaridade, influenciam e sustentam um sistema patriarcal no país.

Para compreender essa conjuntura sul africana, é importante retroceder historicamente na construção político-social do país. Logo, o apartheid é um marco histórico na África do Sul, que ainda influencia as desigualdades de gênero, raça, renda, entre outros, localmente. "O apartheid foi uma forma mais rigorosa e difundida de um sistema social e político que 
predominou desde que os colonos brancos assumiram o poder na África do Sul em meados do século XVII, subjugando os habitantes originais.” (STONE, 2008, p. 16-17).

Como dito anteriormente, as matrizes do apartheid surgiram durante a colonização, contudo, somente em 1948 foi oficializado, após as eleições, com a vitória do partido nacionalista. Essencialmente, buscou separar as culturas Africâner e Inglesa das culturas locais, o que resultou em uma separação e hierarquização entre brancos e negros. As medidas tomadas para a realização da segregação, eram baseadas em ideias de cientistas, que estavam de acordo com sistema vigente.

A segregação ultrapassou a fronteira das ideias e deixou marcas nas relações sociais na África do Sul, nas quais impactaram também, o futuro das mulheres. Uma das normas aprovadas no período, foi a chamada Lei do Amor, essa por sua vez, visava a proibição de relações sexuais entre membros de diferentes grupos raciais. Entretanto, diante das punições, as mulheres recebiam castigos mais severos, diferentemente dos homens que, quase sempre, saíam ilesos ou impunes.

Outro importante aspecto foi, mesmo com a limitação de espaços, serviços, produtos para os indivíduos negros, somente os homens obtinham uma certa liberdade para estar em espaços públicos. Com o reforço das leis de passe - um cartão de identificação a fim de monitorar a entrada de negros na área de pessoas brancas - as mulheres foram relegadas ao espaço doméstico. Tal fato ocorria devido a proibição, até 1956, da retirada de passes para as mulheres negras.

Como consequência, as ideologias simbólicas do apartheid construíram instituições sexistas e racistas, logo, além de sobreviver as humilhações diárias, advindas do estado e da sociedade, os homens sentiam a necessidade de defender sua masculinidade. Assim, conforme Lyn Snodgrass (2015), chefe do departamento de pesquisa políticas e defesa da Universidade Nelson Mandela, na África do Sul, a maior parte da violência é perpetrada por homens negros.

Apesar das explicações anteriores sobre as causas da violência de gênero, surgem questionamentos quanto a persistência do problema. Quando questionado sobre o assunto, Pio Penna Filho (2019) alegou: “a África do Sul, assim como outros países africanos, possui um histórico de violência enraizado nas instituições, que denotam uma sociedade altamente patriarcal até hoje, o apartheid faz parte disso. O país é muito perigoso para as mulheres”.

Lyn Snodgrass também afirma que a maioria da população da África do Sul que vive abaixo da linha da pobreza é feminina. Logo, de acordo com o estudo "Violence against Women in South Africa - A Country in Crisis" (2017), realizado pelo "Centre for the Study of Violence 
and Reconciliation", acredita-se que a violência de gênero também está relacionada a diferença socioeconômica, uma vez que há uma subserviência das mulheres aos homens no alcance e controle dos recursos morais e materiais.

Não obstante, ainda consoante o estudo, além do apartheid, a continuidade desse quadro tem relação com os dilemas na aprendizagem sociocultural do que é "aceitável" na sociedade, com as lacunas na implementação e efetivação de normas contra a violência de gênero, além de questões psicossociais. A junção desses aspectos forma um panorama de normalização de uma hierarquia de poder masculina sobre a feminina e, consequentemente, da violência perpetrada contra as mulheres.

Através de entrevistas realizadas para o relatório "Crime against Women in South Africa" com homens e mulheres sul-africanos, percebeu-se essa realidade. "A primeira pergunta sobre as atitudes aos entrevistados foi se, em geral, é aceitável para um homem bater numa mulher. Estima-se a partir da pesquisa que 3,3\% dos homens e 2,3\% das mulheres na África do Sul pensam que é aceitável para um homem bater numa mulher”. A partir de então, entende-se que a desigualdade de gênero está enraizada e naturalizada no seio social, inclusive entre uma parcela da população feminina.

\section{$4 \mathrm{O}$ exercício das Ongs como rede de atuação mundial}

No Direito Internacional os Estados são os principais atores, "eles são os sujeitos primários e fundadores da sociedade internacional" (NAVARRO, 1979, p.221). Entretanto, para além dos Estados, outras instituições são aceitas como atores e contribuintes da ordem mundial, sendo uma delas as Organizações Internacionais (OIs). Por sua vez, "as Organizações Internacionais, para poderem cumprir suas funções, também devem ter personalidade jurídica de Direito Internacional". (CARESIA, 2007, p.4).

Assim como os Estados e as OIs, as Organizações Não Governamentais (ONGs) fazem parte da rede de atuação mundial, no entanto, de forma diferenciada. "Elas possuem personalidade jurídica de direito interno de um Estado qualquer que, aos lhes conceder personalidade, a elas delega poderes para prosseguir em suas atividades". (CARESIA, 2007, p.4). Ou seja, ao contrário das citadas anteriormente, as ONGs não possuem caráter jurídico no Direito Internacional Público, logo, necessitam do respaldo de algum país.

As principais delineações das ONGs, segundo Pereira (1995, p.403), são “Associações ou fundações, isto é, pessoas coletivas sem fins lucrativos (o que desde já as distingue das 
sociedades transnacionais), criadas por iniciativa privada ou mista, cujo objetivo é o de influenciar ou corrigir a atuação dos sujeitos de direito internacional, especialmente os Estados Soberanos e as Organizações Internacionais”. Desse modo, as ONGs são pessoas jurídicas desenvolvedoras de atividades no ambiente externo do seu Estado.

Por conseguinte, as características citadas anteriormente demonstram um fortalecimento de atores internacionais para além de Estados, no qual dinamizaram e ampliaram as forças motoras do sistema internacional. Nessa circunstância, grupos organizados não governamentais apresentaram-se atuantes em causas públicas alinhadas aos interesses ou necessidades vigentes. Contudo, "as ONGs também se engajam no embate político em busca de conquistas amplas e de maior alcance, como a criação de uma legislação federal, em torno de um tema específico ou de uma nova política". (SILVA, 2013, p.73).

Porém, antes de obter acesso aos meios institucionais do país beneficiário, as ONGs necessitam superar alguns obstáculos, sendo esses: “a) ganhar acesso ao sistema político e b) formar coalizões vencedoras para alterar decisões políticas de acordo com seus interesses". (RISSE-KAPPEN, 1999, p.25).

A ação das organizações na política doméstica ocorre por meio de interações diretas ou indiretas com os formuladores de políticas públicas, tomadores de decisões ou legisladores. “A atuação dessas organizações junto ao Legislativo geralmente é dirigida a comissões específicas onde tramitam projetos de interesse dessas ONGs ou a indivíduos que tenham papel decisório ou relevante no processo em questão". (SILVA, 2013, p.74). Ou seja, a atividade das ONGs estende-se para além da ajuda humanitária, visto que, infiltra-se nas esferas governamentais e influencia a dinâmica interna.

Diante dessa prática, constata-se a influência das organizações não governamentais nos trâmites das instituições estatais, de forma que ambos os agentes atuam na construção de políticas públicas. Caracteriza-se essa influência como "uma relação entre agentes em que um induz outros a agirem de uma forma que de outra maneira não agiriam." (DAHL,1966, apud VILLA, 1999, p.23). Essas atividades tornam-se mais evidentes a partir do momento em que as ONGs obtêm êxito ao engajar os tomadores de decisões nas causas estabelecidas, "Suas estratégias de mobilização também variam, desde lobby com tomadores de decisão a apoio ao desenvolvimento comunitário à mobilização de milhares de pessoas para manifestações públicas”. (GOHN, 2006, p.335).

Em meio a atuação das Organizações não Governamentais, surgem questionamentos quanto ao seu funcionamento e, principalmente, quanto a sua relação com o Estado beneficiário. 
Isso ocorre, pois, como dito anteriormente, as ONGs possuem uma correlação com um ator estatal, no qual lhe concede personalidade jurídica para atuar no sistema internacional. Entretanto, "a atuação ou "captação" das ONGs como instrumento de política externa gera controvérsias, seja pela desconfiança quanto à intenção da assistência por parte dos beneficiários, seja pelo dispêndio de recursos públicos por parte dos contribuintes de países doadores". (SILVA, 2013, p.52).

Com relação a desconfiança, acredita-se que as ações realizadas pelas ONGs podem transformar-se em extensões da política externa dos países doadores dentro de países estrangeiros. "Argumentamos que agentes transnacionais influenciam estruturas internas em Estados-alvo por meio de organizações da sociedade civil. E que essa influência reflete posturas internas dos estados doadores, ou seja, uma extensão de sua política externa". (SILVA, 2013, p.65). Assim sendo, em alguns casos, cria-se um ambiente de ceticismo entre as duas instituições.

Apesar disso, considera-se que a atuação das ONGs é diferenciada conforme as estruturas internas do Estado em que ela se estabelece. Risse-Kappen constata que as distinções presentes nas estruturas domésticas determinam a variação do impacto de atores transnacionais sobre as políticas. Diante dessa temática, quando questionado em entrevista sobre a atuação e os limites de atividades das ONGs, o Doutor em História das Relações Internacionais, Pio Penna Filho afirmou que o ambiente doméstico dos países receptores influencia a ação das organizações e, mais adiante, complementou com exemplos de países com regimes autoritários e democráticos.

Seguindo essa linha, pressupõe-se que nos sistemas democráticos a execução negativa ou até a "ausência" de ações governamentais que supram as necessidades da população, deixam lacunas apropriadas para a atuação de Organismos Internacionais.

[...] a relação teórica entre o comportamento dos estados em política externa e o comportamento das ONGs é dinâmico e condicional, com a influência das ONGs sobre os comportamentos dos estados dependendo do tipo de regime do seu estado apoiador e da idade das ONGs que o influenciam. [...] Com base em estudos existentes, parece que os estados podem exercer forte influência sobre as ONGs e vice-versa. Portanto, é extremamente confuso compreender a direção da influência entre estados e ONGs. Não é fácil apreender a essência da relação entre estados e ONGs porque as relações-estados - ONGs podem variar de acordo com o tipo de regime e a maturidade das ONGs. Esses dois fatores determinam substancialmente a dinâmica das relações estadosONGs. (KIM, 2011, p.34). 
Não obstante, ainda que existam dúvidas sobre o relacionamento entre as Organizações não Governamentais e os Estados soberanos, ambos fazem parte de uma rede de ajuda mútua. Isso desenrola-se pois, mesmo que as ONGs preencham as lacunas causadas pelo estado, o Estado não pode e não deve ser substituído, em virtude de ações que somente por ele podem ser executadas. "Ações de complementaridade entre Estado e ONGs são nutridas em ambiente propício para que se desenvolvam de forma profícua e, para tal, requerem por parte das organizações não governamentais um grau mínimo de autonomia financeira para garantir sua independência". (CLARK, 1998, p.6).

\section{A atuação das Ongs na África do Sul na questão de gênero}

Com um índice elevado de violência gênero, construiu-se um cenário na África do Sul que evidencia o descaso e a quebra dos direitos humanos no país. Nota-se que as respostas do governo para os crimes não alcançam as expectativas necessárias para erradicar ou amenizar a desigualdade de gênero.

Desse modo, perante números exorbitantes, a atenção de atores internacionais, como Estados nacionais, Organizações não Governamentais (ONGs), Organizações Intergovernamentais, entre outros, voltam-se para o centro de incidência do problema, a fim de promover uma resposta juntamente, ou não, ao governo.

\footnotetext{
Nas sociedades democráticas, é justamente o efeito negativo produzido por um governo soberano ou uma carência não suprida pelos governos, que abre espaço para a ação de novos atores não estatais, muitas vezes transnacionais, mais sensíveis às mudanças no cenário das relações internacionais, onde cada vez mais é incluída e considerada a participação da sociedade civil. (SILVA, 2013, p.63).
}

Em meio a escassez de suporte às vítimas, o contínuo aumento da violência e a carência de respostas jurídicas efetivas, a atuação de ONGs na África do Sul permite um tratamento apropriado aos acometidos, se não pela ajuda humanitária - saúde, educação, segurança - então como grupo de pressão. A partir de então, Menescal (1996) ressalta que as ONGs passam a ser consideradas "portadoras da esperança", constatando-se a crescente canalização de recursos financeiros governamentais para ONGs, sob a rubrica da Ajuda Oficial ao Desenvolvimento. (MENESCAL, 1996, p.31).

No caso sul africano, diversas ONGs de ajuda humanitária, direcionadas para mulheres em situação de vulnerabilidade, instalaram-se no país. Essas por sua vez, podem ser distribuídas 
entre nacionais e internacionais, grupos de pressão, ajuda humanitária, empoderamento, entre outras especialidades. Foram listadas algumas ONGs de origem africana com um protagonismo na questão de gênero na África do Sul, a seguir:

a) Rape Crisis Cape Town Trust: Tem como missão promover a segurança nas comunidades, reduzir o trauma sofrido pelos sobreviventes de estupro, encorajar a denúncia de estupro e trabalhar ativamente para corrigir falhas na legislação.

b) ABANTU: busca fortalecer a capacidade das mulheres de participar da tomada de decisões em todos os níveis, influenciar políticas de uma perspectiva de gênero e abordar desigualdades e injustiças nas relações sociais.

c) Akina Mama wa Afrika: procura construir as capacidades de liderança individual e organizacional das mulheres africanas através de programas de desenvolvimento de liderança, redes, informação e advocacia.

d) The African Woman and Child Features Service (AWC): uma organização não governamental focada na mídia, com uma visão regional e uma visão de mídia que aumenta a aceitação da diversidade e igualdade de gênero para o desenvolvimento eqüitativo.

e) The East African Center: ajuda as comunidades a alcançarem o empoderamento, aumentando a alfabetização de mulheres e crianças, melhorando o estado de saúde e erradicando a pobreza.

f) Forum for African Women Educationalist (FAWE): tem como missão promover a equidade e igualdade de género na educação na África através do fomento de políticas, práticas e atitudes positivas em relação à educação das mulheres.

Essas e muitas outras ONGs fazem parte do enfrentamento e suporte a violência feminina perpetrada no país. Conforme "Violence against Women in South Africa - A Country in Crisis" (2017):

\footnotetext{
Estas organizações, assim como muitos outros, têm ao longo dos anos sido significativas em complementar as intervenções do Estado contra a violência de gênero, e também iniciaram seus próprios programas para lidar com o problema e suas implicações práticas para as mulheres e crianças na África do Sul. No entanto, eles também tiveram seus desafios e limitações, especialmente no que diz respeito ao financiamento e a sustentabilidade dos programas, e em relação aos seus programas de intervenção específicos no combate eficaz da violência na África do Sul. (2017, p.25).
}

Mesmo com a atuação e instalação de diversas ONGs pelo país sul africano, constatase que nem todas as vítimas são amparadas, ainda há um déficit alto quanto ao atendimento das 
pessoas violadas, principalmente em relação as instituições governamentais. Dentre muitas justificativas, isso ocorre, pois, algumas vítimas não se sentem seguras para relatar, ou moram em lugares mais afastados - onde o acesso a atendimentos é mais difícil - mas também ocorre pelo desconhecimento de lugares na qual possa recorrer em casos de violência.

Estimativas do "Statistics South Africa" 2016/17 mostram que apenas 9\% dos lares na África do Sul conhecem um abrigo ou um lugar seguro para as vítimas de violência doméstica. Ainda assim, mesmo quando há um conhecimento sobre os locais de ajuda humanitária, percebe-se diferenças quando a família é formada com pelo menos um homem ou mais, ou apenas mulheres, como é possível analisar o Gráfico a seguir:

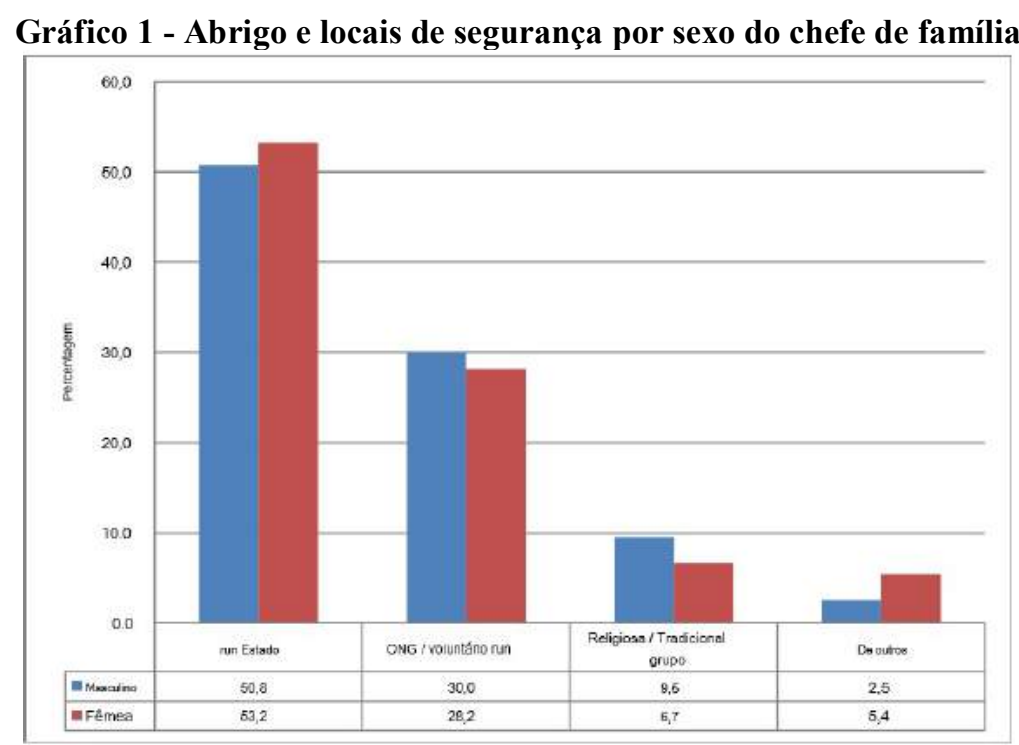

Fonte: Relatório “Crime against Women in South Africa” (2017).

Mesmo que pequena, a diferença entre o conhecimento da existência de ONGs para o suporte de vítimas, entre homens e mulheres na África do Sul, pode contribuir para o aumento de casos. Desse modo, como dito anteriormente, para as vítimas de violência baseadas no gênero que obtém conhecimento sobre o suporte das ONGs, essas instituições tornam-se fonte de esperança e segurança, frente o descaso das ações governamentais assecuratória dos direitos fundamentais.

Assim, as inúmeras ONGs estabelecidas na África do Sul, tanto nacionais, como internacionais, formam uma rede de colaboração, resistência, suporte e pressão ao Governo. Ou seja, as Organizações não Governamentais são fundamentais em um contexto como o sul africano, no qual não há garantia dos direitos sociais presentes na constituição e nos tratados internacionais. 


\section{REFERÊNCIAS BIBLIOGRÁFICAS}

BOSELLI, Giane. No poder e sem violência: dois desafios da inclusão feminina neste século. VIII Congresso Luso-Afro-Brasileiro de Ciências Sociais. Coimbra, 2004.

BOURDIEU, Pierre. A dominação masculina. Rio de Janeiro: Bertrand Brasil, 2002.

BALESTERO, Gabriela soares. GOMES, Renata Nascimento. Violência de Gênero: uma análise crítica da dominação masculina. Revista CEJ. Brasília, 2015.

Crime Against Women in South Africa. Crime Statistics Series Volume V. South Africa, 2018.

CARESIA, Gislaine. Estudos de Direito Internacional - Volume VII - Anais do $4^{\circ}$ Congresso Brasileiro de Direito Internacional. Wagner Menezes (coord.).Curitiba: Juruá, 2006.

Centro Internacional de Políticas para o Crescimento Inclusivo. Proteção social: rumo a igualdade de gênero. Policy in Focus. Volume 14, edição 1º 2017.

DAHL, R. A moderna análise política. Rio de Janeiro: Ed.Lidador Societas, 1966.

GOHN, M. d. G. Teoria dos Movimentos Sociais. São Paulo: Ed. Loyola, 1997.

GOMES, Raquel Gryszczenko Alves. África do Sul, nação-mulher: gênero e narrativa em Mhudi, de Sol Plaatje (1930). Dossiê História das Mulheres, Gênero e Identidades Femininas na África Meridional. Cadernos pagu (49), 2017.

KIM, Youngwan. The Unveiled Power of NGOs: how NGOs influence states' foreign policy behaviors. 2011. $194 \mathrm{f}$. Tese (Doutorado em Ciência Política) - Graduate School of the University of Iowa, Iowa City.

MELO, Aldina da Silva. Em tempos de segregação na África do sul. XXVII Simpósio Nacional de História. Rio Grande do Norte, 2013.

NAVARRO, Aguilar Mariano. Derecho Internacional Privado. Vol .I. tomo I ( $4^{\circ}$ Edición). Espanha, 1979.

SIBANDA-MOYO, Nonhlanhla; KHONJE, Eleanor; BROBBEY, Maame Kyerewaa. Violence against Women in South Africa - A Country in Crisis. Centre for the Study of Violence and Reconciliation. South Africa, 2017.

SILVA, Antonio Augusto G. S. As ONGs como instrumento de política externa no contexto da cooperação internacional para o desenvolvimento: o caso dos Estados Unidos e da Suécia. Programa de Pós Graduação em Desenvolvimento, Sociedade e Cooperação Internacional. Brasília, 2013.

SNODGRASS, Lyn. South Africa: a dangerous place to be poor, black and woman. Nelson Mandela University, 2015. 
STONE, Judith. Retrato em preto e branco: a história verídica de uma família dividida por problemas raciais. São Paulo: Landscape, 2008.

The Constitution: The certification process. Constitutional Court of South Africa. Consultado em 03 de junho de 2019.

UN General Assembly. In depth study on all forms of violence against women. Report of the Secretary-General. United Nations. Consultado em 02 de junho de 2019.

VILLA, Rafael A. Duarte. Formas de influência das ONGs na Política Internacional Contemporânea. Curitiba: Revista de Sociologia e Política. No 12 pp 21-33, 1999.

WHO Factsheet "Violence against women". World Health Organization. Consultado em 02 de junho de 2019. 